\title{
From artefact representation to information visualisation: genesis of informative modelling
}

\author{
Iwona Dudek ${ }^{1}$, Jean-Yves Blaise ${ }^{1}$ \\ ${ }^{1}$ UMR CNRS/MCC MAP 694 gamsau, EAML 184 av de Luminy, \\ 13288 Marseille cedex 09, France \\ \{Iwona.Dudek, Jean-Yves.Blaise\}@map.archi.fr \\ http://www.map.archi.fr
}

\begin{abstract}
In the field of the architectural heritage, the representation of artefacts, particularly for communication purposes, has benefited from the development of computer-based modelling techniques in fields ranging form archaeology to geography. But numerous experts in the above mentioned heritage field have come to question the readability of realistic models inside which the hypothetical nature of the content, a reconstruction, is not clearly assessed. In parallel, research in information visualisation has demonstrated that graphics can support reasoning as well as communication. Our contribution introduces the genesis of an informative modelling methodology in which the representation of architectural objects is used for information search and visualisation. 3D or 2D models localise objects in time, in space, and in a hierarchy of canonical shapes; they are calculated on the fly and deliver information visually. This paper discusses the underlying modelling methodology and applications in investigations about the evolutions of the city of Kraków (Poland).
\end{abstract}

\section{Introduction and research background}

In the field of the architectural heritage, computer graphics have become an increasingly popular tool for communicating results of historical investigations. Virtual reconstructions are often built in order to let a wide public have an idea of how an architectural object may have been like at time $T$ of its evolution. But the use of graphics with this sole goal is often discussed (see [1]) in particular on two grounds:

- A lack of readability due to the fact that the inferences for the reconstruction are hidden in the final result.

- An appalling level of usefulness for the researchers themselves who invest time on a reconstruction that in the end remains a side-effect of the research process, giving no access to deeper information levels.

In other words, the information-gathering effort made in order to produce a reconstruction totally evaporates in the final result. The representation is not linked to the sources of information that helped building it, it is not dynamically updated when new 
findings are done, it does not even mention what at the end of the day seems the most meaningful for researchers - the uncertainty of the original information set.

In parallel, researchers in the field of information visualisation have investigated the use of computer graphics in not only retrieving information but also helping to better sum it up, better understand it. The use of computer graphics as of information discovery tools in the words of J. Kantner [2] is today a reality in many disciplines, but clearly not in the field of the architectural heritage although P. Alkhoven [3] has raised this issue.

Our contribution is an attempt to try and bridge the gap that one can today observe between the above mentioned fields. We try to lay the basis of basis an informative modelling methodology in which the representation of artefacts does not claim veracity, but supports dynamic information retrieval and visualisation.

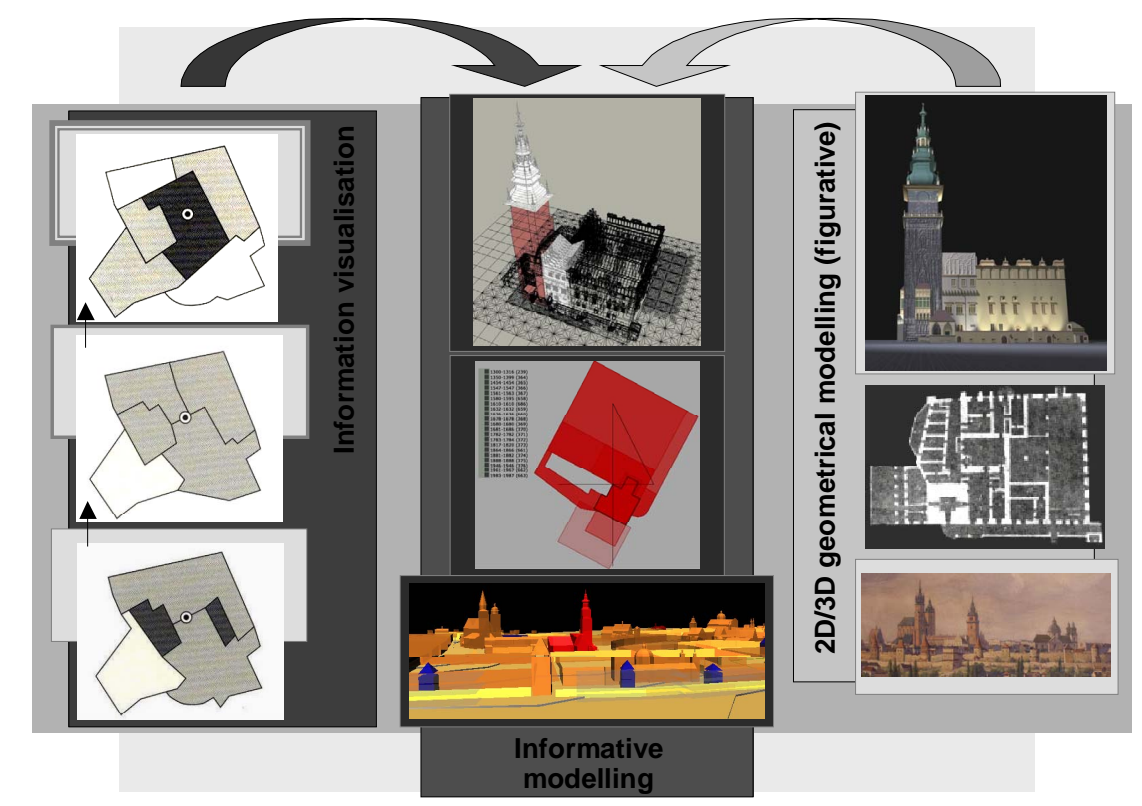

Fig. 1. Filiation of informative modelling. Left, example of insight gained by alternative data distribution accross a territory, from E.R Tufte [5] (graphical analysis of deceased during the London 1859 Cholera epidemic, the circle represents the well finally identified as the source of the disease; only the top distribution indicates this). Right, illustrating the tradition of architectural figurative representation where shape appearances are prominent.

In the field of the architectural heritage, the objects that we strive to represent are most of the time not fully known. Before an actual reconstruction can be represented, its author works out a reconstruction hypothesis basing on pieces of uncertain information (manuscripts, old maps, etc.) that in almost all cases remain partial (see [4]).

What solution does one have when on one hand he does not really know how an edifice was and when on the other hand its computer tool calls for geometric exhaustiveness and trendy realism? What kind of communication, not to mention reasoning, can be done when such a gap exists between a partial knowledge and a thorough geometric 
description? Naturally this question is a central one inside the community dedicated to historical investigations. In that domain gathering, analysing and understanding the architectural documentation is the core task, and visualising and retrieving that information the real goal of representations (see Fig 2). As a result of the ARKIW research programme (see [4]), we came to consider that the solution may well origin not in the field of 3D modelling but in the field of information visualisation, where the role of graphics as defined by E.R. Tufte [5] obviously better suits our goals: "We envision information in order to reason about, communicate, document and preserve that knowledge" [...].
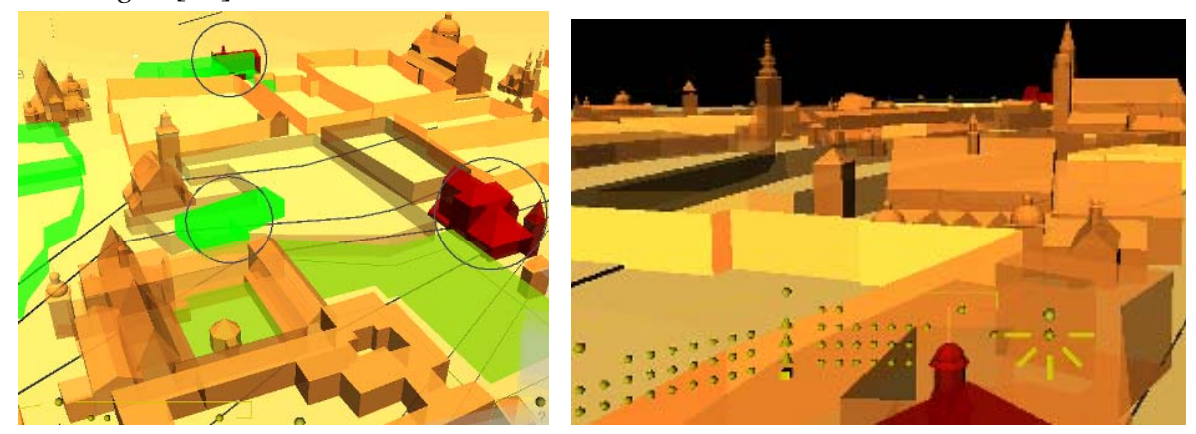

Fig. 2. Left, Graphical appearances adapted to VRML: red or blue colouring marks the use of time analogies, emissive colouring stresses information lacks, translucency mark authenticity of the shapes, green highlighting lets users to check what type of documents are available for each object. Scene for period 1775 showing Franciscans church and monastery (foreground), Dominicans, All Saints, saint Joseph, Saint Peter and Paul, Saint Joseph and Michael, Saint Andrew churches, state of knowledge February 2005.

Right; Interactive VRML selectors in the control panel, allowing for instance queries on various BD from each shape; scene for period 1775, state of knowledge February 2005.

\section{Principles}

During its period of life, an architectural or urban object is in general deeply transformed as a consequence of human activity (ex. adaptations, additions, ..) or of a natural phenomenon (ex. fire, flood, earthquake). We need to document and represent each phase of the edifice's evolution, and will therefore need to formalise a theoretical model of architectural elements in which each element can be given identity persistence, but state evolutions. This is done by providing a static ontology at concept level and a dynamic ontology at instance level, in the words of [7]. The implementation is based on OOP and introduced in [4].

In the proposition we present, architectural and urban concepts are used as filters on the documentation. Each concept features a group of information (graphical and not graphical) that includes a precise definition of its morphology as well as bibliographical references. Yet the documentation is rarely precise enough to thoroughly document all aspects of a physical object. 3D shapes to which we will want to attach pieces of information may then be incompletely defined, and need to be visually marked with an 
indication on what information the proposed shape is based on. Briefly said, we face the necessity to provide a dynamic link between three elements:

- Pieces of information, often vague and uncertain. They will be analysed in order to state at time $T$ of the research what one can say about an architectural object at various $T_{1}-T_{2}$ periods of its evolution.

- A hierarchy of architectural concepts at various scales (urban edifice, covering, arch, ...) instanced as a result of the information analysis process. Each object is natively and dynamically connected to the information sets since representations are calculated as a result of queries on the information sets (see Fig. 4). The representation's level of abstraction and of resolution will match the level of knowledge we have on the object.

- A set of graphical codes used in order to visualise an evaluation of the nature or accuracy of the documentation attached to each architectural object represented in a scene. Codes are not given once for all but reflect the exact content of the documentation at time $T$ of the study. Such codes can show for example the differences between the original parts and elements that were added later; or help in distinguishing what is certain in a hypothesis and what is only hypothetical.

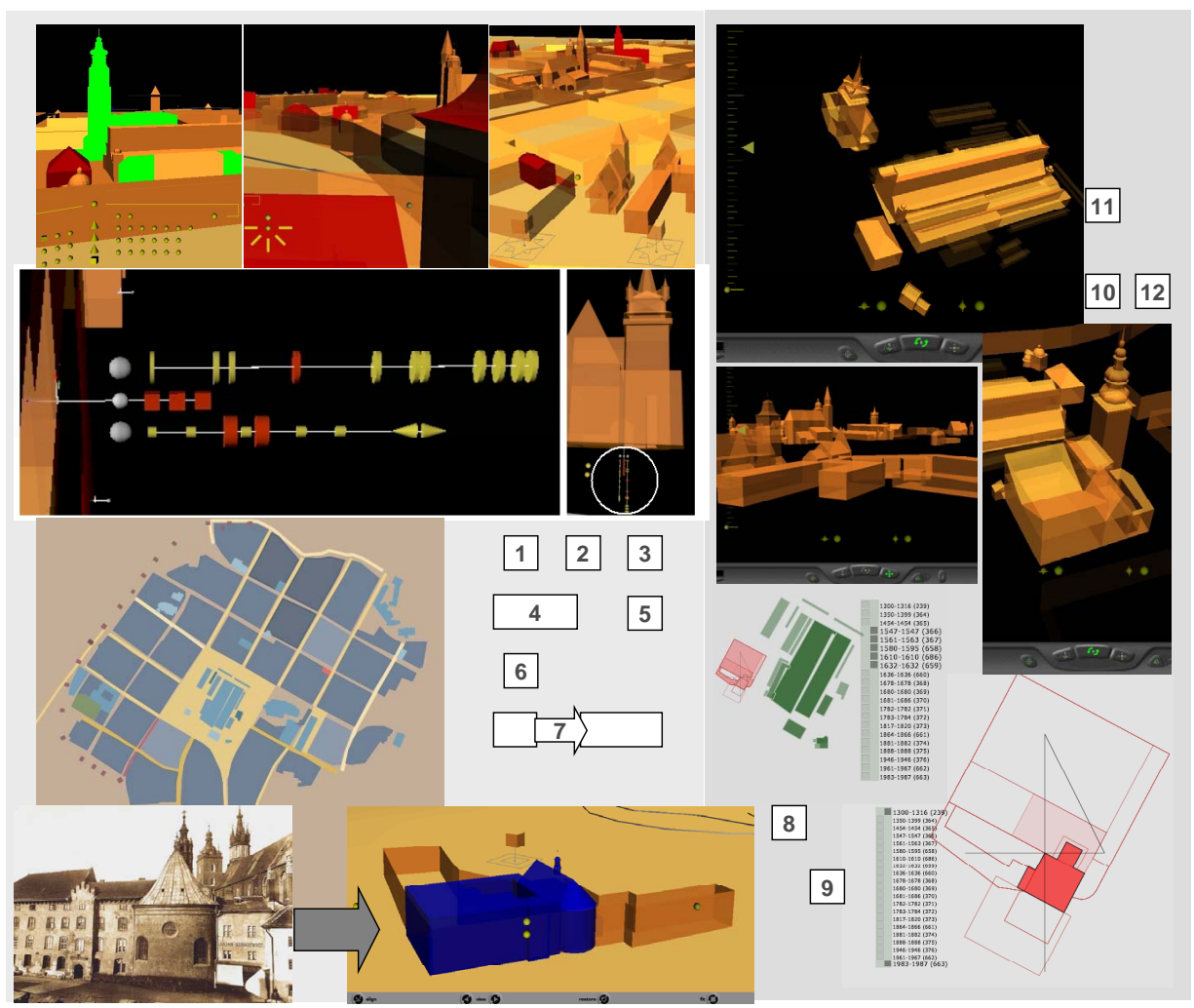

Fig. 3. Alternative types of graphics: 1,2,3 - type A; 4,5 - type B; 6 - type F; 7 - type E; 8,9 - type G; 10,12 - type C; 11 - type D (see following table). 


\begin{tabular}{|c|c|}
\hline Rep & $d s$ \\
\hline $\begin{array}{ll}- \\
\text { ysis }\end{array}$ & $P^{\prime}\left[T_{1}-T_{2}\right] ?$ \\
\hline & $\begin{array}{l}\text { Example : "documentation for objects of type Urban Edifice, Urban Block } \\
\text { and Fortification Units for period 1790-1791" }\end{array}$ \\
\hline$s$ & $\begin{array}{l}\text { What information do we store in the documentation concerning the } \\
\text { shape, function and structure on objects of type } A, B(\ldots) \text { for period } P \text {, } \\
{\left[T_{1}-T_{2}\right] \text { ? }}\end{array}$ \\
\hline [type C]: $T$ & $\begin{array}{l}\text { Example : "style, functions and structure of object Sukiennice (Cloth Hall) } \\
\text { at date 1550". } \\
\text { What are the morphological evolutions of objects of type A,B (...) ? }\end{array}$ \\
\hline $\begin{array}{l}\text { [type } \\
\text { centr }\end{array}$ & $\begin{array}{l}\text { Example : "evolution of objects of type Urban Edifice, Urban Block and } \\
\text { Green Area" } \\
\text { morphological evolutions of object } \boldsymbol{a} \text { showing also surroundings of } \\
\text { object } \boldsymbol{a} \text {, with an additional search criteria that can be instance of the same } \\
\text { concept, distance to object, combination of the two previous. }\end{array}$ \\
\hline [type & $\begin{array}{l}200 \text { meters". } \\
\text { iconographic }\end{array}$ \\
\hline $\begin{array}{l}\text { equi } \\
\text { scen }\end{array}$ & $\begin{array}{l}\text { Example : step } 1 \text { - "all the objects corresponding to I.Krieger's } 1860 \text { s } \\
\text { photograph". } \\
\text { step } 2 \text { - "what other bibliographical items relate to the ele- } \\
\text { ments shown on this photograph". }\end{array}$ \\
\hline$[\mathrm{t}$ & umentation we have on objects of type $A, B(\ldots)$ for period $P$ ", \\
\hline $2 D s$ & $\begin{array}{l}\text { Example : “ documentation for objects of type Urban Edifice, Urban } \\
\text { Block, Fortification Units, Streets and Squares, Green Areas for period } \\
\text { 1820-1821”. }\end{array}$ \\
\hline [type G]: Objec & logical evolutions of object $\bullet$, with the surrounding objects (see \\
\hline witl & t town hall of type Urban Edifice in a \\
\hline
\end{tabular}

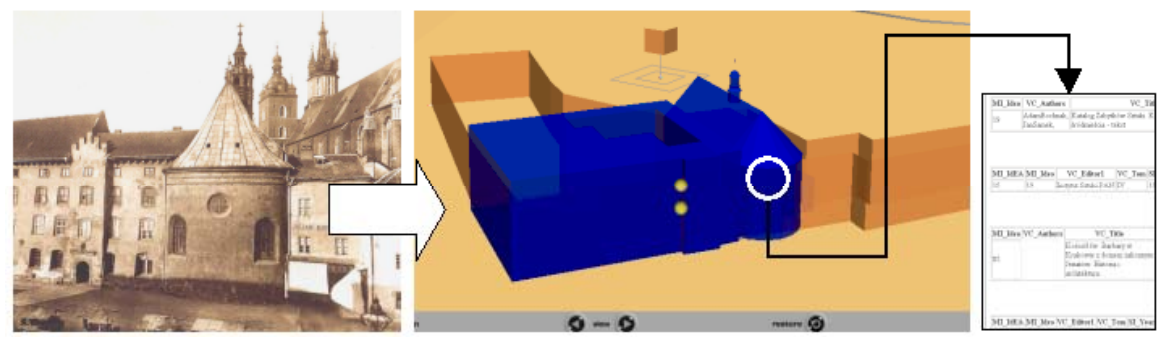

Fig. 4: Type E representation process, a method to for iterative documentation querying. Left an I.Krieger's photograph stored as a iconographic item, middle the corresponding 3D scene calculated by selecting the photograph in the DB Web interface, right the bibliographical items corresponding to ko•ció • $\bullet$ w. Barbary (Saint Barbara's church) at the period of the photograph (1860). 
This methodology has been implemented using a combination of technologies (OOP/ XML-XSLT / SVG / VRML, see [4]) on various case studies in the city of Krakow (Poland), a UNESCO-listed urban ensemble of great architectural value and diversity. It is important to stress that $3 \mathrm{D}$ or $2 \mathrm{D}$ representations are calculated at query-time, and not written once for all, each such representation is calculated after having parsed its current "state of information" (bibliography, morphology, etc..).

We describe architectural objects through a hierarchy of classes with the root class factorising the attributes responsible for representing the documentation's analysis. Each concept isolated detains several blocks of attributes, five mainly qualitative - and nested inside the root class -, one related to the class' morphology - class specific. Each such concept detains methods relevant for persistence handling in XML files and RDBMS context (mySQL). References on the documentation are stored in another database that describes what the data is (a book, a plan, etc.) and attaches this data to information on what it is about (an edifice, a part of an edifice, etc.). Each object is identified by a unique Id, but its morphology may be described in several XML morphology files if the architectural object evolved through time (which of course is quite common). We propose in line with current technical opportunities a solution in which a unique input (the instance's XML sheet) has several outputs (i.e. VRML and SVG).
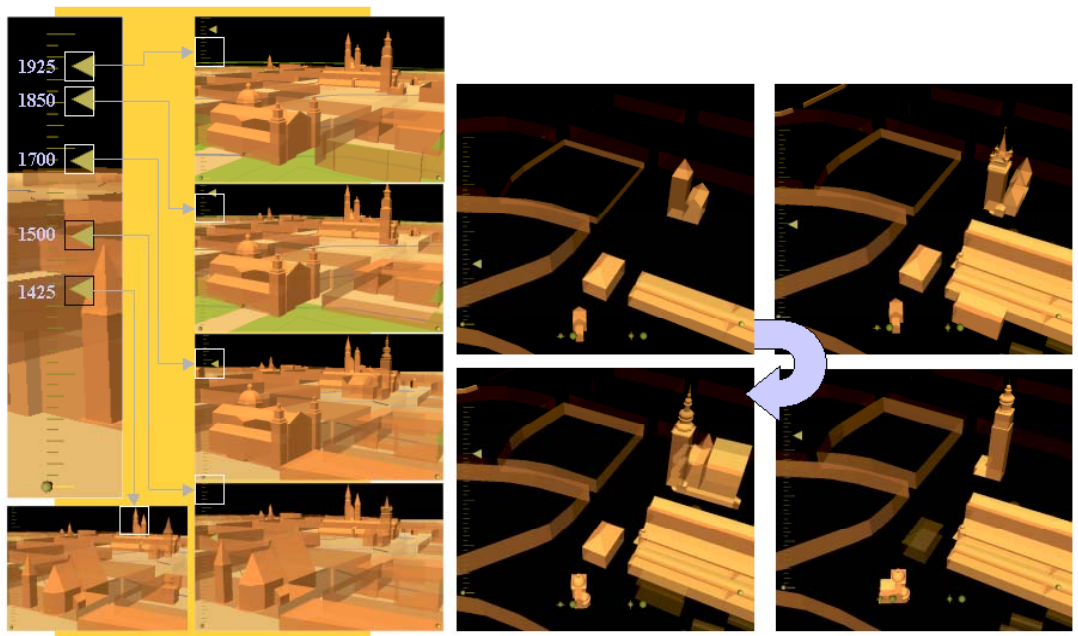

Fig. 5: Left, Timeline scene extracts, view on ulica Anny; on left, the timeline slider, in scenes, note the orientation change in Saint Anne church from late gothic to baroque (1500->1700), state of knowledge February 2005.

Right, Four views from the timeline concerning object Ratusz (Town Hall), state of knowledge December 2004; form top left to bottom right dates shown 1316, 1500, 1725, 1850.

\section{Final observations}

Informative modelling 's goal indeed relates more to J. Bertin's [2] view ( “...a graphic is never an end in itself: it is a moment in, the process of decision making...") 
than to trendy so-called realistic reconstruction. But in the same time the objects displayed inside the graphics we produce "represent visually a physical thing" [6] and therefore match this Spence's definition of scientific visualisation. Informative modelling ultimately intersects questions raised in geometric modelling and in information visualisation. Our research at this stage underlines premises of this methodology:

- Build a theoretical model exploiting what we know about architectural morphologies a priori ${ }^{1}$, a vital point as soon as one wants to allow reuses and comparisons.

- Relate objects to a given architectural scale (from urban layout to simple objects).

- Produce representations dynamically as a reading of the information set's content in order to display a picture at time T of our knowledge. "Dynamic" means here produce graphics at query time, and not produce graphics in which things move.

- Develop a vocabulary of graphical signs and codes that can be used to mark objects in order to visualise the above mentioned uncertainty evaluation.

- Produce representations that can be queried in order to retrieve the elements of information that justify the inferences made for the reconstruction.

- Provide a description framework for the information sets inside which each source can be autonomously attached to architectural objects.

- Choose an abstraction level for the representations that matches the message the representation delivers and/or the object's level of completeness.

- Last but not least, if the graphics does not produce insight on the information sets behind the artefact's shape, consider it worthless.

The Informative modelling methodology, implemented in real-case studies (over 800 edifices or evolutions of edifices, a bibliography of 178 items) does prove at least workable. Our experience also shows that a price has to be paid - faithfulness to the specificity of the architectural heritage, and notably to uncertainty handling.

\section{References}

1. Kantner, J.: Realism vs Reality: creating virtual reconstructions of prehistoric architecture, in Virtual reality in archaeology. Oxford: Archeopress (2000)

2. Bertin, J.: Sémiologie graphique. EHESS (1967) 1998

3. Alkhoven P.: The changing image of the city. A study of the transformation of the townscape using CAD and visualisation techniques. PHD University of Utrecht (1993)

4. Dudek I., Blaise J.Y.: Exploiting the architectural heritage's documentation. I-Know 03, Graz, Austria (2003) 128-134

5. Tufte, E.R.: Visual Explanations. Graphics Press/ Cheshire (1997)

6. Spence, R.: Information visualisation. Addison Wesley ACM Press (2001)

7. Jurisica, I.: Mylopoulos, J. and Yu, E., Ontologies for knowledge management: an information system perspective. Knowledge and Information systems (2004) 380-401

\footnotetext{
${ }^{1}$ i.e the set of fundamental types on which architectural artefacts are based : arches, lintels, etc.
} 